University of Nebraska - Lincoln

DigitalCommons@University of Nebraska - Lincoln

Faculty Publications, Department of Psychology

Psychology, Department of

September 2006

\title{
Domestic violence treatment response and recidivism: A review and implications for the study of family violence
}

\author{
Robert M. Sartin \\ University of Nebraska-Lincoln, rmsartin@syr.edu \\ David J. Hansen \\ Univertsity of Nebraska-Lincoln, dhansen1@unl.edu \\ Matthew T. Huss \\ Creighton University,mhuss@creighton.edu
}

Follow this and additional works at: https://digitalcommons.unl.edu/psychfacpub

Part of the Psychiatry and Psychology Commons

Sartin, Robert M.; Hansen, David J.; and Huss, Matthew T., "Domestic violence treatment response and recidivism: A review and implications for the study of family violence" (2006). Faculty Publications, Department of Psychology. 85.

https://digitalcommons.unl.edu/psychfacpub/85

This Article is brought to you for free and open access by the Psychology, Department of at DigitalCommons@University of Nebraska - Lincoln. It has been accepted for inclusion in Faculty Publications, Department of Psychology by an authorized administrator of DigitalCommons@University of Nebraska - Lincoln. 
Published in Aggression and Violent Behavior 11:5 (September-October 2006), pp. 425-440. Copyright (C 2006 Elsevier Ltd. Used by permission. DOI:10.1016/j.avb.2005.12.002 Available online at www.sciencedirect.com

\title{
Domestic violence treatment response and recidivism: A review and implications for the study of family violence
}

\author{
Robert M. Sartin,* University of Nebraska-Lincoln \\ David J. Hansen, University of Nebraska-Lincoln \\ Matthew T. Huss, Creighton University
}

Submitted May 2004; revised September 2005; accepted December 2005; available online May 2006; in print September 2006.

\begin{abstract}
Although domestic violence is a significant societal problem, which continues to receive public and private sector attention, intervention and treatment programs have proven inconsistent in their success. This paper reviews the published literature on domestic violence treatment efficacy and post-treatment recidivism and explores the related factors. In addition, challenges in the assessment of domestic violence are briefly discussed. Finally, recent developments are discussed along with their potential benefits, and an appeal is made for the need to study domestic violence in the broader context of family violence.
\end{abstract}

Keywords: Domestic violence; Family violence; Recidivism; Treatment response

Domestic violence is a major problem today. Although domestic violence is far from a new occurrence, it was not until the 1970's that it began to be consistently recognized as an important social issue. Since the 1970's, research on domestic violence has proliferated; in fact, a search of psychological references on domestic violence reveals several thousand pieces of literature on the topic. Much of the attention paid to domestic violence is in large measure due to the high prevalence and costs to the victims of domestic violence.

\footnotetext{
* Corresponding author: Syracuse University Counseling Center, 200 Walnut Place, Syracuse, NY 13244.

E-mail: rmsartin@syr.edu
} 
Research has suggested that an intimate partner perpetrates most violence against women. According to findings from the National Victimization Against Women Survey (NVAWS; 1995-1996), over three-fourths of women who have been victimized - either raped and/or physically assaulted - since age 18 were victimized by a current or former intimate partner (Tjaden \& Thoennes, 2000). In fact, the number of female victims is startlingly high; almost one quarter of the women surveyed indicated that they had been physically assaulted and/or raped by an intimate partner in their lifetime. And it is estimated that as many as 1.3 million women are physically assaulted by an intimate partner each year in the United States. Based on the National Crime Victimization Survey (NCVS), an estimated 876,340 females were victims of crimes perpetrated by intimate partners in 1998 (Rennison \& Welchans, 2000).However, the above results clearly demonstrate that the number of victims of domestic violence varies greatly depending on the type of survey or methodology used. In fact, the incidence of domestic violence has been estimated to be higher than measured by either the NCVS or the NVAWS. Using a nationally representative sample of 6002 married or currently cohabiting couples, the 1985 National Family Violence Survey estimated that 8.7 million couples experienced at least one violent incident in 1985 (Straus \& Gelles, 1988). Straus and Gelles estimated that about 6.25 million husbands were physically violent toward their partner and 1.8 million husbands were severely physically violent toward their partner in 1985.

While there are some discrepancies in the number of women who are victims of domestic violence based on methodology for assessing domestic violence, it is generally accepted that there are significant negative consequences for women who are victims of domestic violence. For example, Koss and Hesslet (1992) found that patients with a history of domestic violence visit physicians twice as often as patients without a history of abuse. Moreover, common presenting problems include somatic complaints (e.g., chronic pain, irritable bowel syndrome) (as cited in Phelps, 2000). In addition, Abbott, Johnson, Koziol-McLain, and Lowenstein (1995) found that at least 12\% of women receiving care in the emergency room were the victims of ongoing domestic violence, even though only $2.6 \%$ of the women were actually screened for domestic violence (as cited in Phelps, 2000). Wisner, Gilmer, Saltzman, and Zink (1999) estimated that the direct medical treatment of battered women costs about $\$ 1.8$ billion (as cited in Center for Disease Control, 2002). This large number fails to address the costs of financial support for battered women, legal costs (e.g., cost of police time, court time, cost of incarceration), cost to shelter victims, and cost of therapy. In addition, this number fails to address the potential costs to the children who witness the abuse. Research has shown that children who witness domestic violence also are negatively affected, as children who witness abuse are likely to experience a host of psychological symptoms (Chiancone, 1997). It is estimated that between 3.3 and 10 million children witness domestic violence each year (Witwer \& Crawford, 1995). With all of these costs, the financial and societal impact of domestic violence is truly staggering.

In response to the threat that domestic violence presents, much research and clinical work has been dedicated to determining the causes of domestic violence and how to treat it. Although initial research has focused on the risk factors for domestic violence, more recent research has concentrated on the efficacy of treatment and the occurrence of posttreatment domestic violence recidivism. Unfortunately, results found in the study of domestic violence treatment effectiveness are somewhat equivocal (Rosenfeld, 1992). A recent meta-analysis of 22 studies evaluating treatment efficacy found treatment for domestic violence perpetrators to have only a small effect on post-treatment recidivism; however, this small effect could be very meaningful for some victims of domestic violence (Babcock, Green, \& Robie, 2004). That said, as research continues to increase knowledge about the factors related to treatment efficacy, and risk for posttreatment domestic violence recidivism, the hope is treatment efficacy can be improved.

Given the current focus on treatment and intervention, the goal of this paper is to give an overview of the current literature on domestic violence treatment and intervention effectiveness, with a particular emphasis on post-treatment domestic violence recidivism. With that goal in mind, this paper discusses some of the challenges that impede progress in domestic violence research. From there, the paper goes on to discuss domestic violence treatment response and recidivism. This includes both a general overview of treatment efficacy and recidivism rates along with a review of the factors

found to be related to treatment efficacy and post-treatment recidivism. This paper concludes with a discussion of the implications for research and treatment and suggestions about possible avenues for future research.

\section{Challenges in the assessment of domestic violence}

Despite the dramatic increase in research focused on domestic violence, answers continue to elude researchers and clinicians alike. Several factors complicate the research process and inhibit converting research into clinical 
application. One factor contributing to the difficulty in making progress in research and treatment of domestic violence lies in understanding what constitutes domestic violence. If one were to try to find all of the available literature concerning violence between intimate partners, it would be necessary to search for several terms beyond domestic violence, such as intimate partner violence, partner abuse, and wife battering, along with several other such terms. Further complicating the picture is the fact that some researchers and clinicians define these terms differently, while others use them interchangeably. For instance, some researchers refer to batterers as any perpetrator of domestic violence while others reserve the term batterer for an individual who uses multiple forms of violence (e.g., physical and psychological abuse) to control his/her partner (Feldman \& Ridley, 1995). Thus, when comparing the differences found across studies, one has to be careful to evaluate the different operationalizations of domestic violence. Within this paper we will generally use the terms domestic violence and batterer. Batterer will be used to denote any individual who perpetrates domestic violence. Domestic violence is generally considered to consist of any physical, sexual, or psychological/emotional abuse toward a current or former intimate partner (e.g., spouse, boyfriend/girlfriend). However, much of the research on perpetrators of domestic violence specifically concentrates on physical violence between married or cohabiting intimate partners. Psychological abuse is largely ignored in much of the research. Unless otherwise noted, any mention of domestic violence within this paper will consist of physical violence toward an intimate partner.

Another complication in studying domestic violence is how to measure it. Often domestic violence only comes to the attention of others outside the home when the legal system gets involved. Thus, the most severe cases are more likely to receive attention. For instance, based on the 1985 National Family Violence Survey, only about seven percent of wife assaults are reported to the police (3\% of minor abuse incidents and 14\% of severe abuse incidents) (Kantor and Straus, 1990 and Straus and Gelles, 1988). There are multiple reasons cited throughout the literature as to why the victims of domestic violence do not report it or do not leave the situation (e.g., Barnett, 2001 and Ehrensaft and Vivian, 1996). Most clients who receive counseling do not report domestic violence as a problem to their therapist. Unfortunately, therapists often fail to assess for domestic violence in the couples they treat (e.g., Aldarondo \& Straus, 1994). Failing to assess for domestic violence would seem irresponsible given the high prevalence and the serious risks of domestic violence, particularly in a clinical population (Bograd \& Mederos, 1999). The problems in assessing domestic violence prevalence also present when assessing domestic violence recidivism.

The large variability in samples utilized also limits the findings of many of the studies to the specified population. Most of the major studies in domestic violence research use one of four samples: community, general clinical (e.g., couple seeking marital counseling), clinical (e.g., gender specific domestic violence treatment participant), and courtmandated sample. There are certain characteristics unique to each of these samples; thus, findings using one of the samples do not necessarily apply to a different sample. For instance, individuals who are involved with the legal system and mandated to attend treatment are likely to differ significantly from and evince dissimilar response styles as compared to a community recruited population that knows that the information obtained in assessment is not going to be utilized in an aversive way.

Related to the sampling problem, it is quite difficult to conduct a true experiment on domestic violence interventions. Given the involvement of the legal system, random assignment is quite difficult (almost impossible) to achieve. For instance, more severe offenders are likely to be given more severe criminal sanctions and more likely to be ordered into treatment. Further, even if random assignment was achieved, attrition rates are quite high and negatively affect internal validity. Moreover, a non-treatment control group would be somewhat unethical, given the potential negative consequences for the victim. It is more difficult to isolate the effectiveness of domestic violence treatment given all of the other intervention factors (e.g., victim advocacy, arrest policy, sentencing policy) in communities that have begun to approach domestic violence in a more comprehensive fashion. In addition, there are a variety of ways to measure domestic violence (e.g., self-report, criminal records, partner reports). Each of these methodologies for measuring domestic violence has limitations, and this further contributes to the challenges in the assessment of domestic violence (e.g., Rosenfeld, 1992 and Tutty et al., 2001). Despite challenges in the assessment of domestic violence, research progress has been made and advances continue to be made.

\section{Factors related to domestic violence perpetration, treatment response, and recidivism}

It would be very difficult to summarize all of the relevant literature related to domestic violence risk. In part, this is because there are several related but different conceptualizations of assessing domestic violence risk. Researchers have 
studied domestic violence risk under the following conceptualizations: risk for assault, risk for continued assault, risk for severe assault, risk for frequent assault, risk for assault after intervention, risk for treatment attrition, and risk for domestic homicide. Although there is much overlap in the specific risk factors across these conceptualizations of risk, the conceptualizations appear to have differing patterns (Saunders, 1995). For instance, although a certain variable (e.g., witnessing domestic violence as a child) has a relationship with risk for assault, it does not necessarily have a relationship with risk for severe assault.

Risk for domestic violence assault has been studied longer than risk for recidivism, so it is not surprising that less is known about the risk for post-treatment recidivism. However, clinical treatment issues have motivated much of the recent research, and clinicians and policymakers have become more concerned with the effectiveness of the interventions. Research has concentrated on treatment response (e.g., decrease in marital conflict, improved anger control, improved problem solving skills) in general and more specifically on post-treatment recidivism (e.g., engaging in physical violence against one's partner after treatment).

Perhaps the line of research that deserves the most attention is the study of factors that affect post-intervention recidivism. Individuals who have come to the attention of the legal system and/or have ended up in treatment are likely to represent the more severe end of the continuum for domestic violence perpetration. Here is an easily identified population for intervention, and failure of the intervention is likely to have serious consequences for the victim. Unfortunately, there is much debate about the effectiveness of interventions with batterers (e.g., Babcock et al., 2004, Davis and Taylor, 1999 and Rosenfeld, 1992).

Contributing to the difficulty in evaluating post-intervention recidivism is the fact that the definition of recidivism varies widely across studies. Many studies tend to rely primarily on legal records. However, even within those studies using legal records only, there is considerable diversity. Some researchers tend to consider only further domestic violence convictions as evidence of recidivism, while others also consider attempts to get an order for protection or investigation of domestic violence as evidence of recidivism. Researchers occasionally consider arrests for any violent behavior or any other criminal activity as evidence of recidivism. Other studies utilize partner report (and/or self-report) of physical violence to determine if recidivism has occurred; relying on self-report of the perpetrator has been thought to greatly underestimate reporting of violence and other characteristics, although some have tried to improve the utilization of batterer self-report by adjusting scores for social desirability (Tutty et al., 2001). Rosenfeld (1992) noted that recidivism rates across treatment studies were markedly different depending on the methodology ( $7 \%$ based on criminal records, $36 \%$ based on partner report). Dutton, Bodnarchuk, Kropp, Hart, and Ogloff (1997b) found that for every post-treatment arrest of the domestic violence perpetrators, there were 35 actual assaults based on partner report. Given the large disparity in rates of recidivism based upon the manner in which recidivism is assessed, it is often difficult to compare results across studies.

As for evaluating treatment effectiveness, evaluations of interventions with batterers also are fraught with many problems. For instance, the attrition rate of batterer treatment groups is remarkably high; often as many as $40 \%$ of batterers who attend the initial session fail to complete treatment (Rosenfeld, 1992). This creates difficulty in determining the efficacy of treatment. If one evaluates the effectiveness based on intent to treat (or those assigned to the batterer treatment), one is likely to underestimate treatment effectiveness, since individuals who have attended few or no sessions will be treated as part of the treatment group. However, if one evaluates treatment effectiveness based solely on treatment completion or treatment dosage, then one is likely to overestimate the potential effectiveness of mandating treatment since it is likely that those who complete treatment have certain underlying characteristics that make them more likely to be successful in treatment. That is, individuals who drop out of treatment are likely to possess certain characteristics that make it more difficult for them to benefit from treatment. Some have tried to overcome these problems by using statistical techniques that incorporate corrections for selection bias (Chen, Bersani, Myers, \& Denton, 1989).

When trying to evaluate treatment efficacy and recidivism, it is important to understand that some portion of the batterer population appears to cease engaging in domestic violence without any known intervention. Using telephone survey follow-ups to the 1985 National Family Violence Survey, Aldarondo and Sugarman (1996) found that a significant portion of the respondents ceased engaging in domestic violence for at least two years, and there is no evidence to indicate that they received treatment or other interventions; however, it was not a clinical population. Synthesizing the results of several non-clinical studies, Rosenfeld (1992) estimated that approximately one third of domestically violent males cease to engage in domestic violence without any legal or therapeutic intervention. This apparent spontaneous cessation of domestic violence must be considered when evaluating the post-treatment recidivism rate for batterer groups, as a certain percentage would likely cease battering even without treatment. 
Chen et al. (1989) evaluated the effectiveness of an eight-week treatment for a population of batterers who were mandated by the court to attend treatment; Chen et al. found that the effect of treatment on recidivism was not linear. That is, they found that group members who had attended at least $75 \%$ of the sessions were less likely to recidivate than those who had attended fewer sessions, but they found no effect for treatment when tested linearly as the number of sessions attended. Interestingly, even though all of the men were court-ordered to attend the treatment, $37 \%$ of the participants failed to attend $75 \%$ of the sessions.

Dutton et al. (1997b) also found an effect for domestic violence treatment. Conducting a follow-up evaluation (mean follow-up time of 5.2 years) of court-ordered domestic violence treatment, Dutton et al. compared the recidivism of treatment completers, treatment dropouts, treatment rejects, and treatment no shows using criminal records. Treatment completers had significantly fewer re-assaults (both all assaults and assaults against women) than the other groups with the recidivism ratios of completers, dropouts, rejects, and no shows being .32 and .23 (totals assaults per person and assaults against women per person), .55 and $.50, .81$ and .29 , and .40 and .23 , respectively; actually, no shows have a similar level of assaults against females as treatment completers. Treatment completers were more likely to be employed and were more educated than were noncompleters; this served as a confound in the study.

Hamberger and Hastings (1988) evaluated the outcome of a 15-session skills training group for domestic violence offenders by comparing treatment completers to treatment dropouts, who were significantly more likely to be unemployed. Treatment completers were less likely to violently recidivate in one year (based on a combination of self-report, partner report, and police records). Those who completed treatment showed decreased violence based on the Conflict Tactics Scale (CTS) at post-treatment, and these gains were not lost at follow-up. Although treatment completion tended to decrease/ eliminate physical violence, the authors noted that psychological abuse appeared to continue. Although their experiment contained a confound (i.e., differences in employment status), Hamberger and Hastings' results provide partial support for the efficacy of domestic violence treatment.

Support for the efficacy of domestic violence treatment has not been limited to finding decreases in recidivism rates. For instance, Hamberger and Hastings (1988) found that treatment completers showed significant decreases in dysphoric symptoms (i.e., lower depressive symptoms and lower anger scores). Further, using a self-selected portion of two treatment populations, Dutton, Bodnarchuk, Kropp, Hart, and Ogloff (1997a) found that men who completed treatment showed decreases in level of anger, use of violence, and use of psychological abuse (partner report only) at post-treatment follow-up based on both self-report and partner-report. Impressively, the post-treatment follow-up was conducted on average approximately 27 months after the completion of treatment, showing that the gains were maintained. However, even with the selfselected population, over $40 \%$ of the study volunteers were not located for the follow-up. Some concern exists especially because the subset of participants who were located for the follow-up was older and more likely to be employed.

Several of the previous studies mentioned found pre-treatment differences between the treatment completers and treatment dropouts; particularly, treatment dropouts tend to be younger, unemployed, and less educated. Other research has noted that these factors are related to recidivism (Rosenfeld, 1992). For instance, using telephone survey follow-ups to the 1985 National Family Violence Survey, Aldarondo and Sugarman (1996) investigated the difference between individuals who persist in wife assault and those who cease engaging in wife assault. Younger age, higher levels of verbal aggression, lower SES, and higher levels of relationship conflict were related to engaging in and persisting in wife assault. Thus, studies comparing only treatment completers and noncompleters tend to have significant limitations.

Performing a qualitative evaluation of multiple batterer programs, which use a feminist-cognitive-behavioral framework, Gondolf (2000) found that across the various 3-month follow-up intervals (up to 15 months), most batterers tended to rely almost exclusively on interruption methods to avoid domestic violence assault, although individuals at the longer programs were somewhat more likely to utilize discussion methods; little change in attitudes was noted for the most part. Hamberger and Hastings (1988) also found that personality scores remained unchanged by treatment. Thus, personality and attitudes appear to generally remain the same even after treatment. However, the $25 \%$ of men who noted changing their attitudes towards women and reported using more discussion and respect appeared to be less likely to assault their partners. Unfortunately, sampling problems and lack of controls limit the generalizability. Using a community-recruited sample, Holtzworth-Munroe, Meehan, Herron, Rehman, and Stuart. (2003) found some evidence for the stability of antisocial and borderline traits over a three year follow-up period. The available research seems to suggest that individuals tend to show little attitude or personality change whether or not they receive treatment.

Comparing treatment completers to treatment dropouts, Tutty et al. (2001) evaluated the outcome of treatment for domestic violence perpetration; there were no significant differences found between the two groups (completers and drop- 
outs) on pre-treatment measures. With approximately $68 \%$ of the participants completing treatment, treatment completion was found to be significantly associated with reduced self-reported frequency and severity of abuse (physical and non-physical), higher social support, increased internal locus of control, decreased perceived stress, and improved marital relations. Notably, even after being corrected for social desirability, the post-treatment measure of nonphysical abuse was found to fall below the clinical cutoff, indicating a clinically significant improvement; this was not verified with partner report.

Given that some have found that psychological abuse continues even after treatment and given that some couples indicate difficulty in applying the skills that they learn in gender specific treatment, Johannson and Tutty (1998) evaluated the effectiveness of a 12-week couples group for couples in which both partners had already separately completed a 24-week gender specific group treatment for domestic violence. The couples group was geared toward enhancing relationship functioning through improved problem solving and communication. While the treatment used a relatively small sample size (ten couples completed pre- and post-treatment measures), results of the after-treatment couples group show decreased frequency and severity of psychological abuse and significant improvement in couples functioning; in fact, the improvement was clinically significant as couples moved from the problematic to the average range. However, when followed up a year later, a majority of the couples had experienced an incidence of violence since the group had ended. Given the improvement beyond the gender specific groups, this format could potentially be utilized to help transfer knowledge and skills learned in the gender specific groups into actual use within the couples' relationship.

Many researchers have found an effect for domestic violence treatment, but few researchers have compared the effectiveness of different treatment types. Saunders (1996) compared the relative efficacy of two types of treatment for batterers, feminist-cognitive-behavioral and process-psychodynamic treatment (attrition rates were $38 \%$ and $24 \%$, respectively). In the FCBT group, men who were younger and less educated were more likely to fail to complete treatment. Using multiple methods and multiple sources of information (e.g., partner, self, and legal records), posttreatment follow-up, conducted at an average time of approximately two years after treatment, showed no difference between the two treatments across several measures of change: rates of physical abuse, partner's fear level, style of conflict resolution, and partner's perception of change in the batterer. Thus, both treatments appeared to work equally well. The meta-analysis by Babcock et al. (2004) found no significant differences between treatment modalities on recidivism effect size. However, some treatment factors have been shown to increase the efficacy of treatment. For instance, utilizing conjoint treatment groups and gender-specific treatment groups composed of individuals recruited from the community, Brown and O'Leary (2000) found that husband's alliance with the therapists predicted decreased post-treatment physical and psychological aggression.

Many communities have gone beyond utilizing isolated treatment, using treatment as a part of a more coordinated intervention. Shepard (1992) evaluated the effectiveness of a community intervention program (Duluth Domestic Abuse Intervention Project, DDAIP) by measuring domestic violence recidivism at five-year follow-up; the DDAIP consisted of mandatory arrest policies along with prosecuting and sentencing guidelines for domestic violence. All of the participants in the study attended 22 weeks of treatment with 12 weeks focused on anger management and ten weeks focused on power and control. Forty percent of the participants recidivated (i.e., convicted for domestic assault, were the subject of a protection order, or were suspected of domestic assault by police). Utilizing a discriminant function composed of several variables, Shepard was able to differentiate between those who recidivated and those who did not; however, only a little over $60 \%$ could be correctly classified by the function. Given the question that remains about the efficacy of treatment for domestic violence offenders, many have concentrated on research like Shepard's, trying to determine what factors of the individual make him more likely to recidivate.

Several researchers have found individual and personality characteristics to be related to post-treatment recidivism. For instance, Dutton et al. (1997a) found that personality attributes of domestically violent men were related to treatment outcome. Levels of personality attributes (e.g., borderline, avoidant, antisocial, schizoid, aggressive/sadistic, passive-aggressive, and self-defeating) as measured by the MCMI-II and the Self-Report Instrument for Borderline Personality Organization were found to be positively associated with levels of post-treatment abusiveness. Particularly, measures of borderline personality were more strongly associated with violence severity while measures of avoidant and antisocial personality were more strongly related to psychological abuse.

Using data collected at 3-month intervals (up to 15 months) from batterer program intake in a multi-site evaluation, Gondolf and White (2001) found that $20 \%$ of the domestic violence offenders repeatedly re-assault their partners based on partner report; these repeat re-assaulters reportedly accounted for $80 \%$ of the victim injuries and most of the 
severe incidents. Though most of the repeat re-assaulters showed no major personality psychopathology, a majority of the repeat re-assaulters showed some psychopathic tendency as measured by the MCMI-III; the group of repeat re-assaulters was significantly more likely to show this tendency than were individuals who re-assaulted only once or not at all. Notably, however, personality dysfunction did not discriminate between groups of offenders. The authors asserted that given the relatively low frequency of serious personality psychopathology, standard batterer interventions should be appropriate for most domestic violence offenders.

Other researchers have found that personality characteristics are differentially related to treatment outcome depending on the type of treatment. Saunders (1996) found that feminist-cognitive-behavioral treatment (FCBT) tended to result in less recidivism for individuals with antisocial personality characteristics (measured by the MCMI) as compared to process-psychodynamic treatment (PPT). Also, individuals higher on substance abuse potential and mania were more likely to benefit from FCBT. However, the PPT groups tended to be more efficacious for individuals with dependent personality characteristics. Though Saunders did find significant differences in treatment outcomes related to the interaction of type of intervention and personality characteristics, the actual amount of variance accounted for was actually quite small. Saunders did not find any direct treatment effect for attitudes, moods, or criminal behavior; however, these variables tended to be related to personality characteristics, which were related to treatment outcome.

Several individual factors beyond personality relate to post-treatment recidivism. For instance, Shepard (1992) found that being court-ordered to receive a chemical dependency evaluation and having a history of alcohol treatment were related to increased likelihood of recidivism; this suggests that substance abuse difficulties lead to an increased probability of post-treatment domestic violence recidivism. Further, variables like age, SES, and employment are associated with domestic violence recidivism and/or treatment completion. Murphy, Musser, and Maton (1998) found that lower age was related to higher rates of criminal recidivism for domestic violence offenders. Further, using a volunteer sample of individuals from two batterer treatment programs, Dalton (2001) found with $71 \%$ of the participants in the study completing treatment, only unemployment and number of symptoms of substance abuse were significantly related to treatment noncompletion; however, the effect was relatively small.

Historical and family factors are frequently related to domestic violence perpetration; these factors also are related to an increased risk of post-treatment domestic violence recidivism. For instance, Shepard (1992) found that being abused as a child was somewhat related to an increase in the likelihood of domestic violence recidivism. Saunders (1996) did not find any effect for childhood trauma (e.g., experiencing abuse, witnessing parental abuse) on treatment outcome, although experiencing trauma appeared to be related to antisocial personality, which in turn was related to treatment outcome (post-treatment recidivism). Perhaps the most interesting aspect of historical/family factors and their relationship to domestic violence is the connection that these variables make between domestic violence and broader versions of family violence. Magdol, Moffitt, Caspi, and Silva (1998) found support for developmental antecedents of partner abuse (e.g., family relations, child behavior problems). These findings are impressive given the longitudinal nature of the study of Magdol et al. (using data from the Dunedin Multidisciplinary Health and Development Study). Interestingly, Magdol et al. found only weak correlations between retrospective reports of past problem behaviors and family problems and reports of these variables in previous (prospective) reporting. Finding only weak correlations between prospective and retrospective reporting of family problems and problem behaviors has significant implications for many of the studies of domestic violence that attempt to use retrospective reports. Primarily, this increases the importance of using longitudinal studies in understanding the role of family of origin problems (e.g., experiencing abuse, witnessing domestic violence) in contributing to domestic violence perpetration or victimization, as well as domestic violence recidivism.

Characteristics of the batterer's situation and relationship have been found to be associated with domestic violence recidivism. Harrell and Smith (1996) found higher domestic violence revictimization rates for partners who share biological children (as cited in Mears, Carlson, Holden, \& Harris, 2001). In addition, Mears et al. found that prior victimizations, prior drug use, being African American, and having a lower community SES level were associated with increased probability of domestic violence revictimization; moreover, race and community SES tended to be associated with being revictimized sooner.

Others also have found characteristics of the victim or relationship that indicate a higher risk of being a victim of domestic violence. Using a volunteer sample of women attending educational treatment groups at a local community prevention center and a matched control group, Coolidge and Anderson (2002) found that women who had been in multiple abusive relationships showed greater and more frequent levels of psychopathology than women who had been in only one or no abusive relationship (e.g., self-defeating, dependent, and paranoid characteristics). Further, the women who 
had been in multiple abusive relationships also had higher scores on scales measuring general maladjustment, depression, and PTSD symptoms; though there is no way to determine whether the psychopathology led to being in an abusive relationship or is a product of being in abusive relationships. Regardless, finding psychopathology in victims of multiple abusive relationships has significant implications for treatment and intervention. Measures of relationship conflict have also been found to be predictive of the risk of future domestic violence. For instance, Aldarondo and Sugarman (1996) found that level of marital conflict (one of their malleable risk factors for domestic violence) was a powerful predictor of continued wife assault. Thus, it appears that more than the individual characteristics of the batterer may be important in predicting domestic violence perpetration and post-treatment recidivism; it seems that even characteristics of the batterer's partner and the relationship must be considered when attempting to predict post-treatment domestic violence recidivism.

There has been substantial interest in the effectiveness of using legal interventions to deter domestic violence, especially given the current pro-arrest and mandatory prosecution policies in some communities (Rosenfeld, 1992). However, the findings regarding the effectiveness of legal interventions have been mixed. Using a sample of court cases for domestic violence, Murphy et al. (1998) investigated criminal recidivism at a 12 to 18 month follow-up period from legal intervention. Individuals who received a court order to attend domestic violence counseling were $56 \%$ less likely to have any domestic violence reoffense. Further, likelihood of recidivism tended to decline with increasing levels of intervention system involvement (e.g., only guilty verdict; guilty verdict and probation; guilty verdict, probation, and court order for treatment; guilty verdict, probation, court order for treatment, and successful completion of treatment). Though individuals with more severe histories of domestic violence perpetration tended to receive more intervention system involvement, higher levels of system involvement were related to lower risk of recidivism. Some legal variables are related to domestic violence recidivism on a fairly consistent basis. Dutton et al. (1997b) found that number of pre-treatment crimes was the only variable measured that significantly predicted the amount of time to first assault; Shepard (1992) also found that prior convictions for crimes other than assault were related to likelihood for domestic violence recidivism.

Others have not found an effect for legal intervention. In Murphy et al. (1998), no evidence was found to indicate that frequency and severity of prior assaults was related to recidivism. Studying a population of male domestic violence offenders who had been charged with misdemeanor offenses, Gross et al. (2000) examined the effect of various sentencing options (e.g., advisement, other, community corrections, suspended sentence, and a jail sentence) on recidivism over a follow-up period of 18 to 24 months. None of the sentencing options were found to significantly affect recidivism. Mears et al. (2001) also failed to find differences in domestic violence revictimization rates or time to revictimization when comparing the effects of protection order, arrest, and a combination of protection order and arrest. Moreover, Dalton (2001) found that perception of threat (e.g., consequences from the legal system) had no effect on program completion. However, there is some research that suggests that those who have a higher stake in conformity are less likely to recidivate (Sherman et al., 1992 and Thistlewaite et al., 1998).

Attempts have been made to find differences between individuals who are court-mandated to attend treatment and those who attend treatment voluntarily, though no consistent results have been found. For instance, Dutton et al. (1997b) found that voluntary treatment participants had a significantly longer time until first assault. However, beyond a higher level of perceived stress for court-mandated offenders at post-treatment, Tutty et al. (2001) found no differences between court-mandated and voluntary treatment participants.

Research into the various factors related to domestic violence risk has led to the development and utilization of instruments used to predict domestic violence risk; other researchers have utilized instruments originally developed to predict risk for violence in general. For instance, using a sample of wife assaulters who had been admitted into a maximum-security psychiatric hospital, Hilton, Harris, and Rice (2001) found that scores on the Psychopathy Checklist-Revised (PCL-R) and the Violence Risk Appraisal Guide (VRAG) were significantly related to violent recidivism (correlations of .39 and .42 , respectively). With a mean risk of re-offense time equal to seven years, almost $24 \%$ of the offenders recidivated violently. It is important to note that this sample is highly unusual and unlikely to be representative of most domestic violence perpetrators; for instance, nearly $60 \%$ of the offenders had an index offense of murder or manslaughter. The Spousal Assault Risk Assessment (SARA) Guide has also been found to predict a history of spousal violence in one sample and domestic violence recidivism in another sample (Kropp \& Hart, 2000). In addition, Goodman, Dutton, and Bennett (2000) found that scores on the administration of the Danger Assessment Scale (DAS) to battered women were predictive of domestic violence re-assault within the next three months. Risk assessment instruments have shown some promise in aiding in the prediction of future domestic violence. Unfortunately, examining 
all of the available instruments is outside the scope of the current paper. For a review of the available risk assessment instruments, see Dutton and Kropp (2000).

In addition to the focus on treatment effectiveness, much attention in the recent research has been given to identifying subtypes of batterers, as many feel that batterers are a heterogeneous population. Though much of the recent research has been directed toward trying to identify subtypes of batterers, many unresolved issues remain. The literature has consistently shown that multiple subtypes of batterers exist. Further, there appears to be evidence suggesting differing developmental trajectories through which the subtypes progress. However, there has been some discrepancy over exactly what characteristics comprise the subtypes; particularly, there has been some difficulty differentiating between the generally violent batterer and the borderline/dysphoric batterer. If the batterer subtypes can be consistently identified, then perhaps treatment and prevention could be better targeted; treatments could be specifically tailored to address the needs of each subtype of batterer. Dutton et al. (1997a) indicated that personality factors influence treatment outcome; as a result, the authors proposed that individuals with certain personality characteristics might be more amenable to treatment if matched to specific treatment approaches. In order for this to occur, more research needs to be done on the clinical efficacy of the current batterer subtypes. Some studies have suggested that certain subtypes benefit from different types of batterer intervention, but this is still inconclusive.

Moreover, even if subtypes consistently respond differently to treatment, frontline workers such as clinical treatment providers and judges will need to be able to readily and consistently determine which subtype a batterer belongs to so that he can receive the appropriate treatment. For instance, Holtzworth-Munroe and Stuart (1994) indicated the need for short assessment procedures to allow clinicians and researchers to determine the subtype of batterer in the populations with whom they work. If the current subtypes are not found to have clinical utility then attention will have to be directed elsewhere. For example, it has been suggested by some that even if the empirical typologies do not work out, intervention still needs to make concessions to cultural differences in batterers (e.g., race, socioeconomic status) (Healey, Smith, \& O’Sullivan, 1998).

Holtzworth-Munroe and Stuart (1994) provided a thorough review of the previous literature on batterer typologies; the authors suggested that previous work (both empirical-inductive and theoretical/rational-deductive) had identified three primary dimensions that differentiated between typologies: severity of marital violence, generality of violence (e.g., extrafamilial violence), and personality psychopathology. Holtzworth-Munroe and Stuart proposed that there are three major sub-types of batterers: family only, dysphoric/borderline, and generally violent/antisocial. Family only batterers were hypothesized to have low severity of marital violence, only violence within the family, few legal problems, and low levels of psychopathology (possibly passive-dependent personality traits). Dysphoric/borderline batterers were believed to commit moderate to severe marital violence, have low to moderate levels of extrafamilial violence or legal problems, and were expected to show the highest levels of dysphoria, distress, and emotional volatility (e.g., borderline personality traits). Finally, the generally violent batterers were expected to commit moderate to severe levels of marital violence, engage in higher levels of extrafamilial violence (and experience more legal problems), and experience more psychopathy or antisocial personality disorder. Holtzworth-Munroe and Stuart also hypothesized about the likely difference in correlates (e.g., history of abuse, history of witnessing abuse, drug abuse, deviant peer experiences, and genetic influences) between the proposed typologies.

Using subjects recruited from the community, Holtzworth-Munroe, Meehan, Herron, Rehman, and Stuart (2000) investigated the batterer typology proposed by Holtzworth-Munroe and Stuart (1994). The study utilized both batterer and partner report and used multiple measures and methods where possible. Through clustering analysis, four subtypes of batterers were found; these four subtypes were compared against each other and two groups of nonviolent subjects (maritally distressed and maritally non-distressed); many of Holtzworth-Munroe and Stuart's hypotheses were supported, though the analyses resulted in four clusters instead of three. The extra cluster was hypothesized to be a product of using a community sample. Differences in distal and proximal correlates of marital violence were found among the subtypes (e.g., negative peer involvement, history of child abuse, history of parental rejection, attachment, impulsivity, social skills, attitudes toward violence, and attitudes toward women), suggesting possible developmental differences in trajectories for the batterer subtypes. Holtzworth-Munroe et al. (2003) found some support for the stability of the subtypes, though there was significant overlap of characteristics, particularly between the BD and GVA subtypes. It is important to note that though these findings have helped elucidate the subtypes of batterers in the community, the findings do not necessarily apply to clinical samples of batterers; in fact, to be included in the Holtzworth-Munroe violent sample, only one act of marital violence within the past year was required. This is an important distinction since it seems likely that the most severe cases are over-represented in treatment. 
Waltz, Babcock, Jacobson, and Gottman (2000) also attempted to empirically validate Holtzworth-Munroe and Stuart's (1994) proposed typology using a community recruited sample. Using mixture analysis, the subjects were placed in three clusters based on the entry of five variables: frequency of violence, general violence, antisocial, borderline, and dysthymia. Generally, the typology of Holtzworth-Munroe and Stuart (1994) was supported, though there was some overlap in personality psychopathology between the generally violent (GV) and borderline/dysphoric subtypes (BD); these two subtypes were also found to have witnessed the most severe and frequent parental domestic violence. Both GV and BD men were found to be more emotionally abusive than the Family Only (FO) subtype, and the GV men were found to be high in avoidance and low in anxiety, while the BD men were found to be jealous, low in avoidance, and high in anxiety in their attachment; FO batterers were shown to exhibit high levels of compulsive care-seeking.

There is some debate as to whether empirically-derived clusters of batterers are clinically useful, especially as compared to theoretically-derived clusters of batterers. Using a small sample of batterers in 14-week treatment for domestic violence, Langhinrichsen-Rohling, Huss, and Ramsey (2000) compared empirically derived and clinician theoretically derived typologies using the BDI and the MMPI; police records were also used to derive theoretical subtypes. Five advanced clinical psychology graduate students were unable to reliably sort batterer's individual profiles into subtypes by comparing the individual profile to the composite profiles of the subtypes; further, there was little overlap between the empirically derived and theoretically derived clusters. The theoretically-based subgroups were found to differ significantly on program completion; Family Only (FO) and Borderline/Dysphoric (BD) batterers were more likely to complete the program than were the generally violent $(\mathrm{GV})$ batterers, and BD batterers were found to be more likely to have a history of suicidal ideation. GV batterers from the theoretical clustering were rated by the therapists as more violent, less likely to be violence free at six months after treatment completion, and less likeable. The empirically derived clusters did not appear to perform as well on differentiating treatment outcome variables. Thus, the authors hypothesized that empirical clusters may overestimate clinical utility of batterer subtypes due to significant individual variation from the composite profile.

\section{Directions and considerations for future research}

Though the literature appears to assume that treatment success means a permanent end to domestic violence, it would seem that this criterion misses the mark. For instance, it seems illogical to indicate that pushing one's partner on one occasion is equivalent with beating one's partner on ten occasions. The intent is not to minimize the negative impact of a push or even non-physical abuse, but instead to indicate that if domestic violence treatment significantly reduces the amount and severity of violence that takes place, then it is somewhat effective. Ideally, the goal is to completely eliminate all physical and non-physical domestic violence, but it would be unwise to dismiss current treatment efforts just because the violence was not entirely eliminated. One way to recognize and use this principle is in the conceptualization of recidivism. There is a need to include more than a categorical variable measuring recidivism versus no recidivism. Differences in the number of assaults, length of time between assaults, and rates of rearrest for assault are all important in understanding the effectiveness of domestic violence treatment (Dutton et al., 1997b). By utilizing these varying conceptualizations of recidivism, researchers will be able to give a more complete picture of treatment effectiveness. However, even with using multiple criteria for evaluation, clinicians and researchers will need to evaluate the clinical significance and utility of any changes made in treatment.

In order to allow for an adequate examination of the clinical significance of domestic violence treatment, much work needs to be done in improving attrition rates from batterer treatment programs; several suggestions have been made in the literature. Many advocate for increased contact with the legal system to ensure completion of treatment (e.g., Healey et al., 1998). Currently, the dropout rate for batterers court-mandated for treatment is nearly as high as that of batterers who attend treatment voluntarily (Rosenfeld, 1992). This implies that the perception of consequences from the legal system do not deter program dropout (Dalton, 2001). Increasing the regularity of contact with the legal system, decreasing the time lag from assault to legal consequences, and increasing the sanctions for treatment dropout is expected to decrease treatment attrition (Healey et al., 1998).

The high attrition rates of domestic violence treatment programs could be due in part to failure of treatment to address the individual needs of the participants. Therefore, treatment providers need to assess whether the current treatment models appropriately meet the needs of all the participants. For instance, is the typical confrontation style responsible for treatment dropout? Utilizing less confrontational approaches and increasing therapeutic alliance could likely 
decrease treatment dropout (Augusta-Scott and Dankwort, 2002 and Brown and O'Leary, 2000). Another solution to increase program utility and decrease program attrition is to find ways to motivate batterers to want to change (Augusta-Scott \& Dankwort, 2002). Narrative therapy, for instance, often concentrates on motivating men through convincing them that change is in their own best interest. In addition, Levesque, Gelles, and Velicer (2000) have developed a measure to assess men's readiness to change their violent behavior. The validation study of the measure suggests that it is able to differentiate between men at different levels of readiness for change, though longitudinal studies of its effectiveness are needed. The measure of Levesque et al., URICA-Domestic Violence (URICA-DV), could conceivably allow batterers to be matched to treatment based on their readiness to change. Thus, individuals who demonstrated low motivation for change could first be assigned to groups that are specifically designed to enhance motivation for change; once they are motivated to make changes, these batterers could then be assigned to domestic violence groups that are more directly geared toward behavior change. This process would hopefully decrease domestic violence treatment attrition and improve post-treatment outcome.

Research studies have been unable to show differences in treatment efficacy across treatment types to this point (Babcock et al., 2004, Davis and Taylor, 1999 and Saunders, 1996). There is, however, some evidence to suggest that certain individuals are more likely to benefit from treatment. Research has suggested that individuals with higher levels of personality dysfunction are more likely to be abusive after completing treatment (Dutton et al., 1997a and Gondolf and White, 2001). Research also has suggested that different types of treatment may be differentially effective for subtypes of batterers (Saunders, 1996). Saunders found that individuals with antisocial personality characteristics were more likely to benefit from feminist-cognitive-behavioral treatment, while individuals with borderline personality characteristics were more likely to benefit from process-psychodynamic treatment; however, the effect (interaction of personality and treatment type) was relatively small. Attempts are being made to come up with innovative treatments. One such attempt is the application of dialectical behavior therapy (DBT) to the treatment of domestically violent men (Fruzzetti \& Levensky, 2000). The initial pilot data are promising on both recidivism and attrition, but small and voluntary samples limit generalizability. Innovations such as this offer hope for improvements in domestic violence treatment.

Working with domestic violence victims also appears to have the potential to decrease domestic violence. Though quite controversial, some research has suggested that certain characteristics of females make them more likely to be victims of domestic violence; this does not mean that they are responsible, but it does indicate possible need for intervention with females who have these characteristics. For instance, Magdol et al. (1998) found that a history of problem behaviors for females is related to being a victim of partner abuse. Further, prior victimizations, low SES, and a history of drug abuse also increase the risk of domestic violence revictimization (Mears et al., 2001). This highlights the importance of providing intervention and treatment to females who have been the victims of domestic violence; further, preventive interventions could be targeted to women at high risk for domestic violence victimization. In addition, services targeted to empower women and help them get out of abusive relationships would be useful (Robertson, 1999). Thus, interventions other than clinical work with domestic violence perpetrators could have a significant impact in decreasing domestic violence.

Other intervention systems beyond clinical treatment have received attention in the domestic violence literature. Particularly, the effect of legal system intervention has received much attention. This is particularly important given the shift to pro-arrest and pro-prosecution policies for domestic violence in many districts (Rosenfeld, 1992). There is, however, no clear consensus on the effect of legal system intervention on domestic violence recidivism. Murphy et al. (1998) found that increasing contact with the intervention (legal) system resulted in lower rates of domestic violence recidivism. Gross et al. (2000) and Mears et al. (2001) found no effect of sentencing option on domestic violence recidivism. Given equivocal results of legal intervention, several suggestions have been made in the literature. Healey et al. (1998) suggested the need to expedite domestic violence cases, use centralized dockets, gather broad-based information on the offender quickly, enhance probation supervision, and create a system of supports and protection for the victims. Increasing the effectiveness of the legal system in dealing with domestic violence offenders is likely to be essential in deterring domestic violence.

One issue hypothesized to create difficulty in the study of domestic violence and domestic violence treatment is a belief that batterers are a heterogeneous population. In fact, much of the recent research has been concentrated on determining the subtypes of batterers. The research has generally supported the presence of three subtypes of batterers: family only (FO), borderline/dysphoric (BD), and generally violent (GV). These subtypes of batterers are differentiated by three major characteristics: generality of violence, severity of marital violence, and personality dysfunction (Holtz- 
worth-Munroe et al., 2000). However, there has been some difficulty distinguishing between BD and GV batterers; this probably due in part to the overlap of items on the version of the MCMI and also to the overlap of criteria for various personality disorders. If batterer subgroups can be reliably distinguished then treatment can be targeted to the individual subgroups. It has been noted that it will be important for clinicians to be able to identify the batterer subgroups; short and clear procedures will need to be created to help with this (Holtzworth-Munroe et al.; Langhinrichsen-Rohling, Huss, \& Ramsey, 2000). However, there have been no studies examining batterer subtype and treatment outcome and recidivism, though Langhinrichsen-Rohling et al. did find different therapist predictions about treatment outcome across batterer subtypes. At this point it is unclear whether batterer subtypes will be effective in targeting treatment; that is, it is unclear whether individuals within the batterer subtypes will be respond similarly to the same interventions. Overall, the utility of any subtype will ultimately depend on the degree to which it enables better-targeted intervention and prevention. Current subtypes have not yet proven to be clinically useful, so clinicians will have to continue to find ways to tailor treatments to the particular needs (e.g., sociocultural) of the batterer (e.g., Gondolf \& Williams, 2001).

Beyond the need for effective treatment for domestic violence, there is a question as to whether extensive follow-up is needed. The literature has shown that many batterers recidivate, and even the batterers who do not physically assault their partner again tend to continue with their use of psychological abuse (Hamberger and Hastings, 1988, Johannson and Tutty, 1998 and Rosenfeld, 1992). Moreover, it is unclear whether the skills learned in treatment are generalized to the relationship; there are also questions about how long these gains are maintained, suggesting the need for follow-up interventions. For instance, following completion of domestic violence groups, the batterer and his partner could then participate in couple's groups that would help ensure that the skills learned in the gender specific groups are used within the couple's relationship. In addition, partners of men who exhibit domestic violence need to be informed that the treatment is not a panacea, as the presence of the partner in treatment tends to lower the female partner's thoughts of leaving (Robertson, 1999). Overall, research suggests that benefits could be attained through the utilization of follow-up interventions.

In order to implement effective interventions, reliable assessment procedures are required. To aid in assessment and treatment, several risk assessment instruments have been developed to assess the risk for violence; further, some of these instruments were created specifically to look at the risk for domestic violence (Huss, Covell, \& Langhinrichsen-Rohling, 2006). These instruments represent a means of making better decisions about appropriate legal sanctions and clinical recommendations. These instruments can be utilized pre-treatment to make recommendations for intervention and post-treatment to decide if any follow-up interventions are needed. Though prediction of risk is still inexact, these instruments represent an important tool for aiding clinical judgment. Continued work on these assessment instruments should allow for improved prediction and better risk management.

Despite the development of risk assessment instruments, there are still significant limitations in the assessment of batterers, given that most assessments have tended to rely primarily on self-report; however, researchers have come up with several strategies to overcome these limitations. Some researchers have advocated for using social desirability measures to adjust batterers' self-report given a bias to minimize negative perceptions (Saunders, 1991). Sugarman and Hotaling (1997) performed a meta-analysis and found a low to moderate effect of social desirability on partner violence reporting; offenders' scores on social desirability tend to be negatively correlated with levels of partner violence reporting. However, the effect size may actually be an underestimate given that clinical studies were underrepresented in the meta-analysis. Using social desirability as a covariate could help eliminate some of the variability involved in domestic violence prediction. Given the serious consequences of domestic violence, even a small amount of extra variance accounted for could be important. Further, using partner report whenever possible is likely to increase the accuracy of the data; however, the use of partner report requires instituting safeguards to ensure the safety of domestic violence victims. Ultimately, steps need to be taken to limit reliance on self-report of domestic violence, while at the same time protecting the safety of victims.

Given the difficulty in assessing domestic violence and the factors related to it, several suggestions are noted below. One route for future research is trying to improve the methodology in measuring some of the attitudes that individuals hold, given that current measures of attitudes have not consistently differentiated those who engage in domestic violence from those who do not. Several factors could account for this. For instance, measures about attitudes toward women and attitudes toward violence are likely to result in some level of defensiveness in reporting from some individuals. Moreover, some individuals might even rationally believe in equal rights and responsibilities for both genders, while unconsciously and emotionally they have negative beliefs about females. Utilizing tasks that get at underlying beliefs might better show how attitudes affect domestic violence behaviors. Tasks to measure underlying attitudes 
would probably need to utilize either a cognitive load task or a priming technique task or a combination of the two. Procedures that limit the influence of social desirability could significantly improve assessment reliability and consequently allow for better-targeted interventions.

Next, though legal consequences have not consistently been shown to decrease recidivism, there have been many problems with the research. One possible step to improving the research is measuring how the amount of time between arrest and legal consequences affects rearrest. Behavior research would suggest that decreasing the amount of time between a negative behavior and sanction would decrease the likelihood of the behavior occurring in the future. Further, research should examine the effectiveness of multiple iterations of contact with the legal system. One would expect that for an entrenched behavior that multiple punishments for the negative behavior would be required to extinguish the behavior.

Some other considerations for future research would include comparing iterations through legal system contact only with iterations through treatment only and through combined iterations of both the legal system and treatment. In addition, given the research that suggests that indirect consequences of domestic violence can be more powerful than the direct legal consequences, the legal system needs to be creative in its means of deterring future violence (e.g., placing the pictures of domestic violence reoffenders in the local paper). Also, given that punishment is not as likely to work with individuals who are high in psychopathy, legal intervention can be structured more as negative reinforcement. For instance, an individual can receive a lengthy probation period, and therefore refraining from domestic violence will prevent a lengthy prison sentence.

Further, future research on treatment outcome could include component analysis and process analysis. Given that research has failed to show one treatment to be more effective than another in treating domestic violence, it would be helpful to determine exactly which components of treatment are useful and to examine the manner in which the process of treatment contributes to treatment outcome. For instance, how important is the establishment of therapeutic alliance in the early part of treatment? This analysis of treatment could allow for the creation of more comprehensive treatments that combine the more effective parts of individual treatments.

Perhaps the most important suggestion for future research is the need to study domestic violence as a part of the family violence picture. As one looks over the literature on domestic violence, it is impossible to miss the broad overlap between research on domestic violence and research on child abuse. This overlap of risk factors for family violence was given attention in the 2001 special issue of Aggression and Violent Behavior, and a couple of the articles emphasized the need for increased collaboration across subfields as well as an increased focus on a more global conceptualization of family violence (Heyman and Slep, 2001 and Slep and Heyman, 2001). Further, there appears to be much overlap with studies on general violence and even some overlap with research on juvenile delinquency. If one were to examine this overlap, the research lines would seem to suggest that domestic violence is not a phenomenon that is best understood as an isolated issue, but rather a complicated topic best understood against the backdrop of problems in the family and society in general. While this complexity would appear to make subsequent study of domestic violence more difficult, there is also some benefit to recognizing that domestic violence is only part of a much more complex picture. For instance, interventions can be constructed to address these multiple issues simultaneously; and by better understanding the nature of the problem, services can be more effective and less costly.

Perhaps part of the difficulty in recognizing the overlap between the various literatures is the changing nature of the behavior expression. There is much heterotypic continuity in the display of violent/aggressive behavior over the live span. Thus, though partner abuse may not necessarily be seen in adolescent daters, certain related behaviors can be observed. Through learning to recognize the behaviors that precede partner abuse, intervention can be implemented early to deter much of the later consequences, but also the earlier the intervention is implemented the less entrenched the behavior will become. For instance, Magdol et al. (1998) suggest that adolescence might be the best point of intervention to prevent domestic violence.

Perhaps the best way to understand the development of domestic violence in a more holistic manner is to utilize more longitudinal studies such as the Dunedin study (Magdol et al., 1998). Though they are much more costly and time-consuming, longitudinal studies offer advantages over cross-sectional studies. For example, longitudinal studies, although they would not allow for any definitive proof for causation, would allow better understanding of how various factors leading to domestic violence interact and the process in which they interact. For instance, if marital dissatisfaction (or alcohol abuse) tended to be found prior to marital violence, then this would have several implications for intervention.

On a grand scale, a large longitudinal study specifically following at-risk populations beginning at birth could be very useful. Using a large sample would allow for finding interaction effects among the important factors related to 
domestic violence and family violence, in general. Further, the utilization of a large sample could allow for the identification of protective factors as well as risk factors. Given that all individuals at risk for domestic violence do not go on to commit it or experience it indicates that there are likely certain protective factors at work; the identification of protective factors would likely have an impact on the domestic violence literature, as protective factors have a significant bearing in prevention efforts. Moreover, a large longitudinal study would allow for the examination of the mediating and/or moderating roles of certain variables. For instance, certain risk factors may influence domestic violence through the effects of intermediate variables (mediators), while other risk factors may affect domestic violence differentially based on the level of a third variable (moderator) (Baron \& Kenny, 1986). Understanding the various functions of the multiple risk factors and protective factors would allow for increased theoretical understanding of the etiology of domestic violence and allow for more innovative intervention and prevention strategies.

Using longitudinal studies allows for gathering prospective data, thereby eliminating much of the error that comes with using retrospective reports; this would seem invaluable given the finding of Magdol et al. (1998) of only weak correlations between prospective and retrospective reports of behavior problems and family conflict/violence. Measuring many variables over time would also help to eliminate some competing factors as causing domestic violence. For instance, by measuring both childhood trauma and family conflict, one could determine whether childhood trauma or family conflict in general is related to the perpetration of domestic violence. Moreover, longitudinal studies could increasingly highlight the overlap of domestic violence with other literatures. For instance, results from the Dunedin study suggest that individuals who experience behavioral problems in their teenage years are more likely to be involved in domestic violence. Links like this can aid in targeting prevention/intervention to populations at high risk. Conceivably, domestic violence, child abuse, and juvenile delinquency can be prevented and/or treated with a single comprehensive intervention that is well timed.

Ultimately, domestic violence theorists and clinicians need to recognize the complicated and multifaceted nature of domestic violence. Integrated theories can guide more realistic research, which could in turn provide avenues toward intervention and prevention. What the literature increasingly shows is that the concept of intervention/treatment for domestic violence needs to be expanded. High levels of treatment attrition and the relative ineffectiveness of legal sanctions in isolation suggest the need for a much more comprehensive and integrated community approach to domestic violence (and for that matter, family violence).

Despite lingering disagreement about the effectiveness of domestic violence treatment, it appears that domestic violence treatment results in some positive changes in batterers who complete it (Babcock et al., 2004, Davis and Taylor, 1999, Dutton et al., 1997a, Hamberger and Hastings, 1988 and Tutty et al., 2001). Moreover, batterers who complete domestic violence treatment are less likely to subsequently recidivate and have fewer re-assaults when they do recidivate than those who drop out of treatment (Chen et al., 1989and Dutton et al., 1997b; Hamberger and Hastings; Tutty et al.). However, given the lack of true control groups, it is difficult to determine the extent to which batterer treatment is actually responsible for the lower recidivism rates. Individuals who drop out of batterer treatment programs tend to be younger, of lower SES, and unemployed; these same characteristics are associated with domestic violence recidivism. Thus, this factor serves as a confound in the studying treatment outcome.

Beyond studying treatment efficacy and domestic violence post-treatment recidivism, much emphasis has been placed on studying factors related to treatment efficacy and post-treatment recidivism. Many factors, in addition to personality factors, have been found by researchers to be related to domestic violence recidivism including variables in the following domains: historical/family factors, legal interventions, and characteristics of the relationship/situation. Some examples of characteristics are related to treatment efficacy and post-treatment recidivism include substance abuse, younger age, childhood trauma, sharing biological children, lower SES, and marital conflict. These variables that are related to domestic violence treatment efficacy and recidivism suggest some possible points of intervention. For instance, substance abuse treatment could be offered concurrently with domestic violence treatment in order to reduce recidivism. Further, intervention/prevention in cases of marital conflict might also help reduce domestic violence recidivism; Holtzworth-Munroe et al. (1995) developed a prevention program for engaged and newly married couples who are at risk for domestic violence. Continued research on factors that are related to treatment outcome are critical if interventions are to be successful, as understanding related factors will allow more targeted and comprehensive interventions.

Complications in the study of domestic violence continue to exist (e.g., methodology in assessing domestic violence and recidivism, treatment attrition); however, research is working to counter many of these complications. For example, researchers are utilizing multiple methods and multiple respondents to measure domestic violence, and researchers are 
working toward finding ways to decrease treatment attrition. Increasing knowledge of factors related to domestic violence and improvements in batterer typologies along with advances in risk prediction instruments and improved coordination with the legal system have led to substantial gains in the understanding of domestic violence. As a consequence, research on domestic violence treatment effectiveness and post-treatment recidivism has made significant progress. However, continued work and ingenuity are required if domestic violence and its impact are to be greatly curtailed.

\section{References}

Aldarondo and Straus, 1994 - E. Aldarondo and M.A. Straus, Screening for physical violence in couple therapy: Methodological, practical, and ethical considerations, Family Process 33 (1994), pp. 425-439.

Aldarondo and Sugarman, 1996- E. Aldarondo and D.B. Sugarman, Risk marker analysis of the cessation and persistence of wife assault, Journal of Consulting and Clinical Psychology 64 (1996), pp. 1010-1019.

Augusta-Scott and Dankwort, 2002 - T. Augusta-Scott and J. Dankwort, Partner abuse group intervention: Lessons from education and narrative therapy approaches, Journal of Interpersonal Violence 17 (2002), pp. 783-805.

Babcock et al., 2004 - J.C. Babcock, C.E. Green and C. Robie, Does batterers' treatment work? A meta-analytic review of domestic violence treatment, Clinical Psychology Review 23 (2004), pp. 1023-1053.

Barnett, 2001- O.W. Barnett, Why battered women do not leave, part 2, Trauma, Violence, and Abuse 2 (2001), pp. 3-35.

Baron and Kenny, 1986 - R.M. Baron and D.A. Kenny, The moderator-mediator variable distinction in social psychological research: Conceptual, strategic, and statistical considerations, Journal of Personality and Social Psychology 51 (1986), pp. 1173-1182.

Bograd and Mederos, 1999 - M. Bograd and F. Mederos, Battering and couples therapy: Universal screening and selection of treatment modality, Journal of Marital and Family Therapy 25 (1999), pp. 291-312.

Brown and O'Leary, 2000 - P.D. Brown and K.D. O'Leary, Therapeutic alliance: Predicting continuance and success in group treatment for spouse abuse, Journal of Consulting and Clinical Psychology 68 (2000), pp. 340-345.

Center for Disease Control, 2002 - Center for Disease Control, Intimate partner violence fact sheet, Center for Disease Control, National Center for Injury Prevention and Control, Atlanta, GA (2002).

Chen et al., 1989 - H. Chen, C. Bersani, S.C. Myers and R. Denton, Evaluating the effectiveness of a court sponsored abuser treatment program, Journal of Family Violence 4 (1989), pp. 309-322.

Chiancone, 1997 - J. Chiancone, Children: The forgotten victims of domestic violence, Child Law Practice 16 (1997), pp. 69-75.

Coolidge and Anderson, 2002 - F.L. Coolidge and L.W. Anderson, Personality profiles of women in multiple abusive relationships, Journal of Family Violence 2 (2002), pp. 117-131.

Dalton, 2001 - B. Dalton, Batterer characteristics and treatment completion, Journal of Interpersonal Violence 16 (2001), pp. $1223-1238$.

Davis and Taylor, 1999 - R.C. Davis and B.G. Taylor, Does batterer treatment reduce violence? A synthesis of the literature. In: L. Feder, Editor, Women and domestic violence: An interdisciplinary approach,, The Hayworth Press Inc., New York (1999), pp. 69-93.

Dutton et al., 1997a - D.G. Dutton, M. Bodnarchuk, R. Kropp, S.D. Hart and J.P. Ogloff, Client personality disorders affecting wife assault post-treatment recidivism, Violence and Victims 12 (1997), pp. 37-50.

Dutton et al., 1997b - D.G. Dutton, M. Bodnarchuk, R. Kropp, S.D. Hart and J.P. Ogloff, Wife assault treatment and criminal recidivism: An 11-year follow-up, International Journal of Offender Therapy and Comparative Criminology 41 (1997), pp. 9-23.

Dutton and Kropp, 2000 - D.G. Dutton and P.R. Kropp, A review of domestic violence risk instruments, Trauma, Violence, and Abuse 1 (2000), pp. 171-181.

Ehrensaft and Vivian, 1996 - M.K. Ehrensaft and D. Vivian, Spouses' reasons for not reporting existing marital aggression as a marital problem, Journal of Family Psychology 10 (1996), pp. 443-453.

Feldman and Ridley, 1995 - C.M. Feldman and C.A. Ridley, The etiology and treatment of domestic violence between partners, Clinical Psychology: Science and Practice 2 (1995), pp. 317-348.

Fruzzetti and Levensky, 2000 - A.E. Fruzzetti and E.R. Levensky, Dialectical behavior therapy for domestic violence: Rationale and procedures, Cognitive and Behavioral Practice 7 (2000), pp. 435-447.

Gondolf, 2000 - E.W. Gondolf, How batterer program participants avoid reassault, Violence Against Women 6 (2000), pp. $1204-1222$.

Gondolf and White, 2001 - E.W. Gondolf and R.J. White, Batterer participants who repeatedly reassault: Psychopathic tendencies and other disorders, Journal of Interpersonal Violence 16 (2001), pp. 361-380.

Gondolf and Williams, 2001 - E.W. Gondolf and O.J. Williams, Culturally focused batterer counseling for African American men, Trauma, Violence, and Abuse 2 (2001), pp. 283-295.

Goodman et al., 2000 - L.A. Goodman, M.A. Dutton and L. Bennett, Predicting repeat abuse among arrested batterers: Use of the Danger Assessment Scale in the criminal justice system, Journal of Interpersonal Violence 15 (2000), pp. 63-74.

Gross et al., 2000 - E.P. Gross, E.P. Cramer, J. Forte, J.A. Gordon, T. Kunkel and L.J. Moriarty, The impact of sentencing options on recidivism among domestic violence offenders: A case study, American Journal of Criminal Justice 24 (2000), pp. 301-312.

Hamberger and Hastings, 1988 - L.K. Hamberger and J.E. Hastings, Skills training for treatment of spouse abusers: An outcome study, Journal of Family Violence 3 (1988), pp. 121-130.

Healey et al., 1998 - K. Healey, C. Smith and C. O'Sullivan, Batterer intervention: Program approaches and criminal justice strategies (NCJ 168638), U. S. Department of Justice, Offices of Justice Programs, Washington, DC (1998).

Heyman and Slep, 2001 - R.E. Heyman and A.M.S. Slep, Risk factors for family violence: Introduction to the special series, Aggression and Violent Behaviour 6 (2001), pp. 115-119. 
Hilton et al., 2001 - N.Z. Hilton, G.T. Harris and M.E. Rice, Predicting violence by serious wife assaulters, Journal of Interpersonal Violence 16 (2001), pp. 408-423.

Holtzworth-Munroe et al., 1995 - A. Holtzworth-Munroe, H. Markman, K.D. O'Leary, P. Neidig, D. Leber and R.E. Heyman et al., The need for marital violence prevention efforts: A behavioral-cognitive secondary prevention program for engaged and newly married couples, Applied and Cognitive Psychology 4 (1995), pp. $77-88$.

Holtzworth-Munroe et al., 2000 - A. Holtzworth-Munroe, J.C. Meehan, K. Herron, U. Rehman and G.L. Stuart, Testing the Holtzworth-Munroe and Stuart (1994) batterer typology, Journal of Consulting and Clinical Psychology 68 (2000), pp. 1000-1019.

Holtzworth-Munroe et al., 2003 - A. Holtzworth-Munroe, J.C. Meehan, K. Herron, U. Rehman and G.L. Stuart, Do subtypes of martially violent men continue to differ over time?, Journal of Consulting and Clinical Psychology 71 (2003), pp. 728-740.

Holtzworth-Munroe and Stuart, 1994 - A. Holtzworth-Munroe and G.L. Stuart, Typologies of male batterers: Three subtypes and the differences among them, Psychological Bulletin 116 (1994), pp. 476-497.

Huss et al., 2006 - M.T. Huss, C.N. Covell and J. Langhinrichsen-Rohling, Clinical implications for the assessment and treatment of antisocial and psychopathic domestic violence perpetrators, Journal of Aggression, Maltreatment, \& Trauma 13 (2006), pp. 61-87.

Johannson and Tutty, 1998 - M.A. Johannson and L.M. Tutty, An evaluation of after-treatment couples' groups for wife abuse, Family Relations 47 (1998), pp. $27-35$.

Kantor and Straus, 1990 - G.K. Kantor and M.A. Straus, Response of victims to the police and police to the assaults on wives. In: M.A. Straus and R.J. Gelles, Editors, Physical violence in American families, Transaction Publishers, New Brunswick, NJ (1990), pp. 473-487.

Kropp and Hart, 2000 - P.R. Kropp and S.D. Hart, The Spousal Assault Risk Assessment (SARA) Guide: Reliability and validity in male offenders, Law and Human Behavior 24 (2000), pp. 101-118.

Langhinrichsen-Rohling et al., 2000 - J. Langhinrichsen-Rohling, M.T. Huss and S. Ramsey, The clinical utility of batterer typologies, Journal of Family Violence 15 (2000), pp. 37-54.

Levesque et al., 2000 - D.A. Levesque, R.A. Gelles and W.F. Velicer, Development and validation of a stages of change measure for men in batterer treatment, Cognitive Therapy and Research 24 (2000), pp. 175-199.

Magdol et al., 1998 - L. Magdol, T.E. Moffitt, A. Caspi and P.A. Silva, Developmental antecedents of partner abuse: A prospective-longitudinal study, Journal of Abnormal Psychology 107 (1998), pp. 375-389.

Mears et al., 2001 - D.P. Mears, M.J. Carlson, G.W. Holden and S.D. Harris, Reducing domestic violence revictimization: The effects of individual and contextual factors and type of legal intervention, Journal of Interpersonal Violence 16 (2001), pp. 1260-1283.

Murphy et al., 1998 - C.M. Murphy, P.H. Musser and K.I. Maton, Coordinated community intervention for domestic abusers: Intervention system involvement and criminal recidivism, Journal of Family Violence 13 (1998), pp. 263-284.

Phelps, 2000 - B.P. Phelps, Helping medical students help survivors of domestic violence. MSJAMA, 283, 1199 [On-line serial] (2000) Available: www.ama-assn. org/sci-pubs/msjama.

Rennison and Welchans, 2000 - C.M. Rennison and S. Welchans, Intimate partner violence (NCJ 178247), U.S. Department of Justice, Bureau of Justice Statistics (2000).

Robertson, 1999 - N. Robertson, Stopping violence programmes: Enhancing the safety of battered women or producing better-educated batterers?, New Zealand Journal of Psychology 28 (1999), pp. 68-84.

Rosenfeld, 1992 - B.D. Rosenfeld, Court-ordered treatment of spouse abuse, Clinical Psychology Review 12 (1992), pp. $205-226$.

Saunders, 1991 - D.G. Saunders, Procedures for adjusting self-reports of violence for social desirability bias, Journal of Interpersonal Violence 6 (1991), pp. 336-344.

Saunders, 1995 - D.G. Saunders, Prediction of wife assault. In: J.C. Campbell, Editor, Assessing dangerousness: Violence by sexual offenders, batterers, and child abusers, Sage Publications, Thousand Oaks, CA (1995), pp. 68-95.

Saunders, 1996 - D.G. Saunders, Feminist-cognitive-behavioral and process-psychodynamic treatments for men who batter: Interaction of abuser traits and treatment models, Violence and Victims 11 (1996), pp. 393-414.

Shepard, 1992 - M.F. Shepard, Predicting batterer recidivism five years after community intervention, Journal of Family Violence 7 (1992), pp. 167-178.

Sherman et al., 1992 - L.W. Sherman, D.A. Smith, J.D. Schmidt and D.P. Rogan, Crime, punishment, and stake in legal conformity: Legal and informal control of domestic violence, American Sociological Review 57 (1992), pp. 680-690.

Slep and Heyman, 2001 - A.M.S. Slep and R.E. Heyman, Where do we go from here? Moving toward an integrated approach to family violence, Aggression and Violent Behavior 6 (2001), pp. 353-356.

Straus and Gelles, 1988 - M.A. Straus and R.J. Gelles, Violence in American families: How much is there and why does it occur? In: E.W. Nunnally, C.S. Chilman and F.M. Cox, Editors, Troubled relationships, Sage Publications, Newbury Park, CA (1988), pp. 141-162.

Sugarman and Hotaling, 1997 - D.B. Sugarman and G.T. Hotaling, Intimate violence and social desirability: A meta-analytic review, Journal of Interpersonal Violence 12 (1997), pp. 275-290.

Thistlewaite et al., 1998 - A. Thistlewaite, J. Wooldredge and D. Gibbs, Severity of dispositions and domestic violence recidivism, Crime and Delinquency 44 (1998), pp. 388-398.

Tjaden and Thoennes, $2000-\mathrm{P}$. Tjaden and N. Thoennes, Full report of the prevalence, incidence, and consequences of intimate partner violence against women: Findings from the National Violence Against Women Survey (NCJ 183781), U. S. Department of Justice, Office of Justice Programs, Rockville, MD (2000).

Tutty et al., 2001 - L.M. Tutty, B.A. Bidgood, M.A. Rothery and P. Bidgood, An evaluation of men's batterer treatment groups, Research on Social Work Practice 11 (2001), pp. 645-670.

Waltz et al., 2000 - J. Waltz, J.C. Babcock, N.S. Jacobson and J.M. Gottman, Testing a typology of batterers, Journal of Consulting and Clinical Psychology $\mathbf{6 8}$ (2000), pp. 658-669.

Witwer and Crawford, 1995 - M.B. Witwer and C.A. Crawford, A coordinated approach to reducing family violence: Conference highlights, U. S. Department of Justice, Office of Justice Programs (1995). 